\title{
Writing legibility of selected effectors: Evidence for a generalized motor program?
}

\author{
Patricia Paulsen Hughes, Madison Gilliam Beanland, \\ Tyler Danielson, Bert H. Jacobson*
}

Oklahoma State University, Stillwater, USA

* Corresponding author: bert.jacobson@okstate.edu

\begin{abstract}
The purpose of the study was to determine if a generalized motor program (GMP) exists for writing, as has been previously reported. Beginning with a 1942 experiment by Lashley, and continuing with a 1976 (Raibert) example, writers of some motor learning texts have asserted that one can write with different effectors (nonpreferred hand, mouth, foot, etc.) and the results are quite similar, thus demonstrating that writing is a generalized motor program. The task has not been reported in recent literature. In order to determine if the results reported were generalizable, the researchers recruited 31 individuals who volunteered to write a short sentence under five conditions: 1) preferred hand, 2) preferred hand with wrist stabilized, 3) non-preferred hand, 4) mouth, and 5) foot. Participants ranged in age from 19 to 75 and were grouped as follows: $<25 \mathrm{yrs}, \mathrm{n}=15 ; 25-44 \mathrm{yrs}, \mathrm{n}=6 ;>44, \mathrm{n}=10$. Although all of the samples were legible in Conditions 1 and 2 , legibility deteriorated significantly in Conditions 4 and 5 . Contrary to expectations, there were no significant differences between the samples produced by based on age groupings. The authors concluded that most adults cannot write legibly with their mouths or feet, contrary to what has been previously reported.
\end{abstract}

\section{KEYWORDS}

Marc Raibert; handwriting; preferred hand; non-preferred hand; motor program

DOI

$10.14712 / 23366052.2020 .8$

\section{INTRODUCTION}

In the first few grades of elementary school, children begin learning academic content, but also establishing the groundwork for learning to express themselves through the written word. Handwriting is considered to be integrating motor programs, visual-spatial skills, and setting of parameters for letter formation (Graham, Struck, Santoro, \& Berninger, 2006). For some children, handwriting is the first instance in which coordination of all three systems is tasked simultaneously. Handwriting, as with all physical skills, requires effectors (skeletal muscle fibers) which are under manual or

(c) 2020 The Authors. This is an open-access article distributed under the terms of the Creative Commons Attribution License (http://creativecommons.org/licenses/by/4.0), which permits unrestricted use, distribution, and reproduction in any medium, provided the original author and source are credited. 
voluntary control. With practice, one develops a certain style, which is accompanied by motor programing, a term used to describe performance of certain motor skills in an automatic, spontaneous fashion (Shusterman, 2011). The brain/hand motor memory has been thought to be the most powerful of people's memories (King, 2015).

For the most part, handwriting is still taught in elementary schools in the U.S. About $90 \%$ of teachers stated that they provided about 15 minutes per day on instruction (70 minutes per week), and about $80 \%$ of the districts require teaching of handwriting (Graham, Harris, Mason, Fink-Shorzempa, Moran, \& Saddler, 2008). Typically, handwriting continues to improve for the first few years (Accardo, Genna, \& Borean, 2013; Overvelde \& Hulstijn, 2011), and speed and legibility continues improving through fourth or fifth grade (Bara \& Morin, 2013). When some elementary schools experimented with children composing by keyboard and by hand, almost all students composed superior essays by hand, both in terms of speed and content (Connelly, Gee, \& Walsh, 2007).

Despite the proliferation of computers/voice-activated devices/phones with keyboards, Feder and Majnemer (2007) maintain that legible handwriting remains an important life skill that deserves continued emphasis from educators and health practitioners. Handwriting is a critical part of childhood development and can have negative consequences if not accomplished.

Even though computer keyboarding is progressively becoming the norm, vital cognitive benefits are lost with the disappearance of handwriting (Berninger, 2012; Zubrzycki, 2012) because handwriting engages more networks within the brain, which aids in recall (Berninger, 2012).

Failure to attain handwriting competency during the early school age years often has far-reaching negative effects on academic success and self-esteem (Feder \& Majnemer, 2007). In a review of 13 studies, the authors (Graham, Berninger, Abbott, Abbott, $\&$ Whitaker, 1997) concluded that handwriting fluency was moderately correlated with measures of writing achievement. Jones and Christensen (1999) estimated that after controlling for reading ability, the ability to form accurate letters accounts for about two-thirds of the variance in written expression.

Handwriting is integrally linked to composition. Impaired handwriting can impact the ability:

1) to be accessible to others (Graham, 1999),

2) for a composition to be perceived as being of good quality (Marshall \& Powers, 1969),

3) to put thoughts onto paper if the writer is trying to remember how to form letters (Scardamalia, Bereiter, \& Goleman, 1982),

4) to develop writing competencies (McCutchen, 1995), and

5) to make the writer believe he/she can become a writer (Berninger, Mizokawa, \& Bragg, 1991). Thus, handwriting is a critical developmental process in early education.

In becoming adept at writing, the practice of writing letters, joining them together to form words, joining those to create sentences, etc., the mechanical part eventually becomes, for most people, a rather effortless process that is executed without thought, and is known as a motor program. Handwriting has been considered a generalized motor program (GMP) (Carter \& Sharpiro, 1984), and if practiced, has the potential 


\section{a Able was \& ere \& saw Elba \\ - Able wasel ere \& save Elba \\ - Able was a ere s saw Elba \\ - Clble was es ene saw Elba \\ - Chble war ere s naw Esba}

Figure 1 Writing sample in motor learning books used to illustrate GMP

Used by permission of author (Raibert, 1977).

to develop into an instantaneous action (Schmidt, 1991; Schmidt \& Lee, 2014) with invariant writing patterns (Castiello \& Stelmach, 1993).

A GMP is one in which the timing/rhythm (an invariant feature) remains the same for different movements, but each movement itself can vary in terms of size, direction, force, speed, angle, or sets of muscles (effectors) used. In other words, in a tennis game with a skilled player, the same GMP for a forehand stroke occurs to contact the ball even though the ball may be coming at a different angle, speed, or direction from one shot to the next (Schmidt \& Lee, 2014).

In the case of the effectors or size varying while accessing the same GMP, when one writes a word on a piece of paper, it should look almost identical if written on a blackboard. Thus, a person with a motor program for cursive handwriting should still be able to perform the same action on a grand scale, say a blackboard, and the samples should be easily recognizable as coming from the same person (Merton, 1972).

Beginning with the first edition of Richard Schmidt's Motor Learning and Performance: From Principles to Practice (1991), the author(s) included five writing samples written by one person with preferred hand, preferred hand stabilized, non-preferred hand, teeth, and foot. Each of the sentences is easily recognizable as coming from the same person, and all samples are approximately the same size, with similar spacing between letters, equivalent pressure, and the same slant. Results of the original study by Raibert (1976) have been included in each subsequent edition of Schmidt's book, up to and including the current fifth edition. Raibert $(1976,1977)$ drew two conclusions from the writing samples in his 1976 paper: 1) that motor programs are independent of effectors or kinematic considerations, and 2) a GMP can be translated into directions for "muscles, mechanics, and sensors of a particular limb" (p. 10, 1976).

A similar example was illustrated by Schmidt and Lee (2011), by two different participants who wrote with preferred and non-preferred hand, right mirror image, left mirror image, and teeth (Lashley, 1942). Again, samples were easily identifiable as being written by the same person, albeit one of the participant's trials was notably larger than the other samples. The authors suggested that the spatial pattern was invariant, even though different effectors were used. 


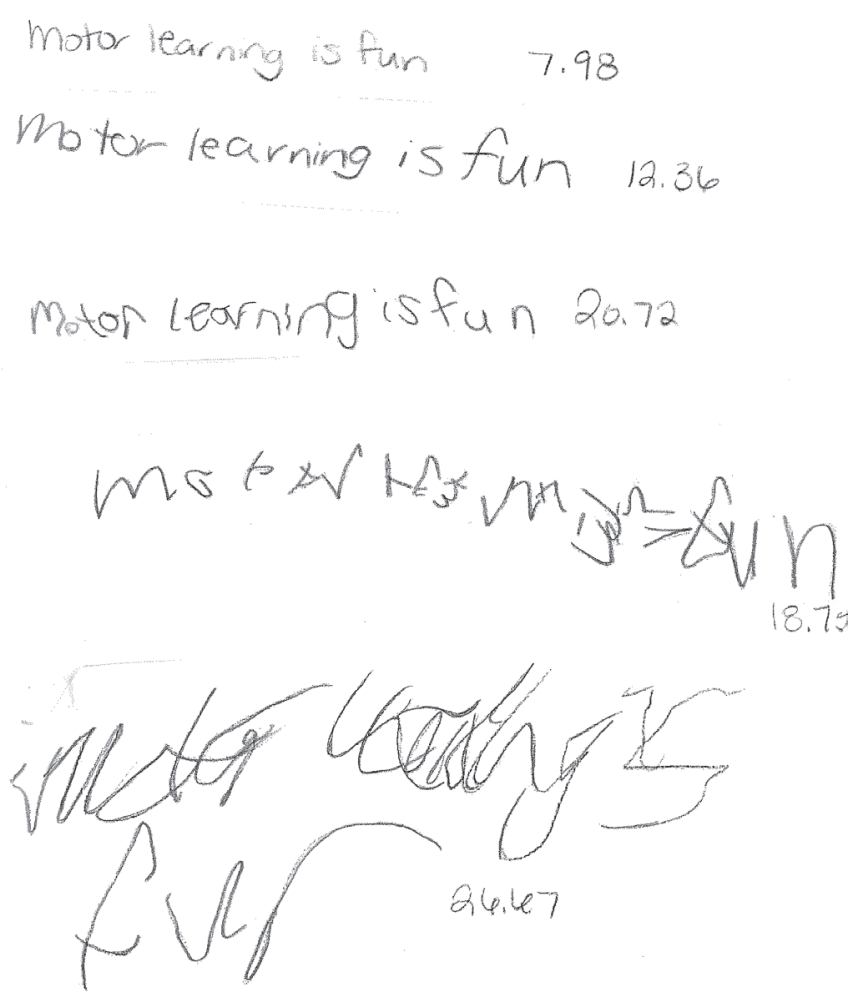

Figure 2 Average writing (score of 20/25)

Bernstein (1967) asserted that handwriting with different effectors shows a high degree of motor equivalence. Merton (1972) demonstrated the difference in writing on a wall versus a tabletop, and though the size was considerably larger, the actual letters themselves were very similar in character, suggesting that though the effectors were different for the two trials, the same motor program was accessed. Motor equivalence was also seen through the qualitative findings of spatial similarities across familiar writing patterns or similar letter forms (Castiello, \& Stelmach, 1993).

More recently, Li et al. (2015) found that that there were no significant differences in the size or number of motor units activated for movement between dominant and non-dominant hands. They reasoned that since muscle activation is quite similar, the actual action carried out might be similar, as well. Changing the orientation of the surface used to write on, such as a desk versus a chalkboard, changes how the effector approaches the movement, however. Factors such as gravity increase the acceleration of downward strokes, and more effort is needed for upward strokes (Phillips \& Ogeil, 2010). In this case, the motor program appears to adjust for the added orientation.

Additional factors were also present when attempting to write with effectors that differ from the usual mode of writing, such as writing on the floor using the foot. Phillips and Ogeil (2010) drew the same conclusion as Raibert (1976), in that similar outcomes may be achieved when using multiple joints, such as comparing movements between the shoulder and wrist. In a recent publication, Osiurak, Lesourd, Delporte 
\& Rossetti (2018) reported that, regardless of the effector, and without any instruction, participants maintained approximately the same amount of force (left and right hand, right elbow and right foot) with different effectors.

However, others have found that the dominant hand and the non-dominant hand patterns exhibited different movement characteristics, indicating that learned writing patterns share only the very highest and most abstract representation suggesting that theme similarities may not be sufficient in themselves to demonstrate that writing with different effectors is controlled by a single, effector-dependent representation (Castiello \& Stelmach, 1993; Wright, 1990).

After one of the authors watched several hundred students over the course of the past twelve years attempting to write with the foot and mouth, she has observed that not a single student ever produced the high quality of the writing reported by Raibert $(1976,1977)$. When one of the authors queried Richard Schmidt (lead author of Motor Learning and Performance) about the discrepancy between the completely legible writing samples provided by Raibert and current university students' failure to meet up to the presented standards, Schmidt responded "if people can't write with their feet, the world should know about it. At least, the textbook writers should stop claiming that they can" (personal correspondence, 2008). Tim Lee, a co-author of Schmidt's 5th edition of the text further suggested, that since 1976, when Raibert authored the original paper, handwriting may have become an especial skill, not a GMP, but because of massive amounts of practice with the preferred hand, a very specific motor program that is usable only for the preferred hand. In other disciplines, this phenomenon is known as a splinter skill. Lee suggested that perhaps handwriting is still a GMP for adults who have spent decades handwriting, but not for the young generation who grew up with computers, and suggested a comparison of university students and their parents' capabilities (personal correspondence, 2008).

Although GMPs have been studied in regard to other effectors, the writing task included in Raibert's 1976 and 1977 papers has not been replicated. The purposes of the current study, therefore, were to determine whether 1) contemporary adults have a GMP for writing with different effectors and 2) to determine if age is a factor in writing quality across conditions.

\section{METHOD}

\section{Participants}

Following Institutional Review Board (IRB) approval, during the spring semester of 2018, a convenience sample of university students and adults in the community was approached to participate, and those wishing to do so read and signed an IRB approved consent form. In total, 31 participants (male $n=17$, female $n=14$ ) provided complete data. Age was separated in the following manner: $<25 \mathrm{yrs}, n=15 ; 25-44 \mathrm{yrs}$, $n=6 ;>44, n=10$. The ages ranged from 19 to 75 .

Data were collected individually at a site and time of the participants' choosing. No attempt was made to diversify the sample by sex or ethnicity, however, researchers attempted to recruit approximately equal numbers of participants in each group.

Each participant received several pieces of standard size paper, a short "golf" pencil $(9 \mathrm{~cm})$, and packaged alcohol wipes. The first condition was to write with the pre- 
ferred hand in their usual form (print or cursive). In the second condition, participants used the preferred hand with the wrist stabilized by the contralateral hand so the larger effectors of the arm completed the task. The third condition was writing with non-preferred hand and the fourth condition was to write while holding a short "golf" pencil in the mouth. The fifth condition was holding the pencil between the toes using the preferred foot. The researchers taped the paper to the floor and the pencil to the foot so enough pressure could be maintained to write, and to minimize movement of the pencil. Each condition consisted of three trials in which participants wrote as normally as possible, "Motor learning is fun".

Previous studies (Graham, Weindtraub, \& Berninger, 1998) have identified numerous elements contributing to handwriting legibility (spacing between letters and spacing between words, alignment, size and slant of letters, and letter formation accuracy). In the current study, the investigators chose to focus on letter formation alone as the main criterion for determining legibility. Researchers chose the most legible sample of the three trials in each condition and determined a readability score of 1 to 5 . Out of the 18 letters in the trial, a score of $1=0-4$ letters legible, $2=5-8$ letters legible, $3=9-12$ letters legible, $4=13-16$ letters identifiable, and $5=$ legibility of $17-18$ letters. Across the five conditions, a possible cumulative score of 25 was attainable.

Interrater reliability was established in a two-step process. In the first step, two of the investigators independently determined the most legible sample in each condition for each participant and scored the sample based on the criteria outlined above. In the second step, all three researchers met together, compared scores, discussed scores that differed, and reached a consensus, resulting in $100 \%$ interrater reliability.

\section{Data Analysis}

The researchers computed descriptive statistics for demographic variables. All data were subjected to correlation crosstabs and repeated measures ANOVA conducted with SPSS v. 24 (IBM, 2018).

\section{RESULTS}

Three-fourths (74.2\%) of the participants recalled being graded on their handwriting in elementary school. The vast majority of the participants (87\%), regardless of age, stated they had completed homework during secondary school by hand, not using typewriter or computer. Approximately half $(n=15)$ said that their handwriting quality was important to them, $11(35.5 \%)$ said that quality was sometimes important to them, and $5(16.1 \%)$ said that quality was unimportant. Of the sample, $6(19.4 \%)$ had completed high school, 14 (45.2\%) earned some college credit, 7 (22.6\%) had earned a bachelor's degree, and 4 (12.9\%) reported having a graduate or professional degree.

The participants reported how much they currently wrote by hand: less than $25 \%$ (25.8\%), 25-50\% (25.8\%), 50-75\% (32.3\%), and more than $75 \%$ (16.1\%) of writing was still done by hand. As expected, the scores for dominant hand and dominant hand stabilized were the highest with the scores progressively decreasing with each subsequent condition (Table 1). Across all five conditions, means ranged from 5.00 (dominant hand) to 2.73 (foot) with a total mean of 4.22. The most legible condition, not surprisingly, was dominant hand, with all participants receiving a " 5 " for readability. 
Although scores for conditions 1 and 2 were nearly identical, writing legibility degraded rapidly across the remaining conditions.

Table 1 Means and standard deviations for each condition

\begin{tabular}{l|c}
\hline Variables & Means SD \\
\hline Dominant hand & $5.00(0.00)$ \\
\hline Rigid wrist & $4.96(0.18)$ \\
\hline Non-dominant hand & $4.77(0.49)$ \\
\hline Mouth & $3.61(0.92)$ \\
\hline Foot & $2.74(1.18)$ \\
\hline
\end{tabular}

A repeated measures ANOVA for the five conditions resulted in statistically significant differences $(F(4,120)=72.127, p<0.001)$ among the conditions. A Newman-Keuls post hoc test indicated that, with the exception of rigid wrist and dominant handwriting, all subsequent combinations were significantly different, with the combination of dominant hand and non-dominant hand and the combination of rigid wrist and non-dominant hand reaching significance at $p<0.05$ (Table 2). No significant difference $(p=0.22)$ was found between handwriting quality and age group.

Table 2 Results of repeated measures ANOVA for each combination of dependent variables

\begin{tabular}{|c|c|c|c|}
\hline Variables & Means SD \pm & df & $P$ value \\
\hline $\begin{array}{l}\text { Dominant hand } \\
\text { Rigid wrist }\end{array}$ & $\begin{array}{l}5.00(0.00) \\
4.96(0.18)\end{array}$ & 54 & 0.321 \\
\hline $\begin{array}{l}\text { Dominant hand } \\
\text { Non-dominant hand }\end{array}$ & $\begin{array}{l}5.00(0.00) \\
4.77(049)\end{array}$ & 54 & $0.014^{*}$ \\
\hline $\begin{array}{l}\text { Dominant hand } \\
\text { Mouth }\end{array}$ & $\begin{array}{l}5.00(0.00) \\
3.61(0.92)\end{array}$ & 54 & $<0.001^{* *}$ \\
\hline $\begin{array}{l}\text { Dominant hand } \\
\text { Foot }\end{array}$ & $\begin{array}{l}5.00(0.00) \\
2.74(1.18)\end{array}$ & 54 & $<0.001^{* *}$ \\
\hline $\begin{array}{l}\text { Non-dominant hand } \\
\text { Rigid wrist }\end{array}$ & $\begin{array}{l}4.77(0.49) \\
4.96(0.18)\end{array}$ & 54 & $0.045^{*}$ \\
\hline $\begin{array}{l}\text { Non-dominant hand } \\
\text { Mouth }\end{array}$ & $\begin{array}{l}4.77(0.48) \\
3.61(0.92)\end{array}$ & 54 & $<0.001^{* *}$ \\
\hline $\begin{array}{l}\text { Non-dominant hand } \\
\text { Foot }\end{array}$ & $\begin{array}{c}4.77(0.48) \\
2.39\end{array}$ & 54 & $<0.001^{* *}$ \\
\hline $\begin{array}{l}\text { Rigid wrist } \\
\text { Mouth }\end{array}$ & $\begin{array}{l}4.96(0.18) \\
3.61(0.92)\end{array}$ & 54 & $<0.001^{* *}$ \\
\hline $\begin{array}{l}\text { Rigid wrist } \\
\text { Foot }\end{array}$ & $\begin{array}{l}4.96(0.18) \\
2.39(2.74)\end{array}$ & 54 & $<0.001^{* *}$ \\
\hline $\begin{array}{l}\text { Foot } \\
\text { Mouth }\end{array}$ & $\begin{array}{l}2.39(2.74) \\
3.61(0.92)\end{array}$ & 54 & $<0.001^{* *}$ \\
\hline
\end{tabular}

${ }^{*} p<0.05,{ }^{* *} p<0.01$ 
The researchers computed correlations to determine whether any variables were related to writing quality. When comparing handwriting quality of those who wrote in cursive $(n=8)$ or print $(n=23)$, the researchers found there was no statistically significant relationship between the two $(p=0.126)$ (Table 3$)$.

Table 3 Spearman rank order correlations by dependent variable

\begin{tabular}{l|c|c|c|c}
\hline Variable & Rigid Wrist & Non Dominant & Mouth & Foot \\
\hline Rigid Wrist & 1.000 & $0.356^{*}$ & -0.078 & 0.273 \\
\hline Non Dominant & $0.356^{*}$ & 1.000 & 0.094 & 0.237 \\
\hline Mouth & -0.078 & 0.094 & 1.000 & $0.426^{*}$ \\
\hline Foot & 0.273 & 0.273 & $0.426^{*}$ & 1.000 \\
\hline
\end{tabular}

${ }^{*} p<0.05$

\section{DISCUSSION}

The purpose of this study was to determine whether 1) adults have a GMP for writing with different effectors, and 2) if mature adults' and young adults' writing patterns differ in quality, independent of effector. We determined from the repeated measures ANOVA that the quality of mouth writing and foot writing was significantly poorer than the other conditions. Additionally, statistical analysis revealed that mature adults' and young adults' writing patterns did not differ in quality independent of effector. In spite of taking into account numerous variables that could potentially influence the quality of writing, the authors were unable to find any variables that accounted for differences in writing quality across the five conditions. All foot and mouth samples were inferior in quality and legibility to the preferred hand samples, both visually and statistically.

The original source of the sample in the motor learning textbook (Raibert, 1977), was a paper generated in 1976 while Raibert was a doctoral student in the Artificial Intelligence Laboratory at MIT, and presented the results of one person (Raibert, 1976). The paper related to computer programming for a robotic arm, and how that could be accomplished. The sample was again included in his dissertation the following year (Raibert, 1977). Richard Schmidt (1991) included the sample in each of the six editions of Motor Learning and Performance. The task does not seem to have been replicated until now.

Samples from conditions 1, 2, and 3 demonstrated the same GMP with respect to size. However, following condition 1, samples in each of the conditions typically became larger, to the point where condition 5 often took more than one page for each of the three trials.

Examination of our writing samples provides support for and against GMPs for writing. It may be argued that the individuals with the best writing showed a GMP, because all of the conditions appeared to be from the same person - the style and shape of the letters were clearly similar, although the size of the letters and variability increased with each condition. However, the vast majority of the participants' attempts on conditions 3,4 , and 5 were vastly inferior to conditions 1 and 2 . When observing 
the majority of our samples, not only were the letters illegible, but there was no consistent spacing, style, or construction of letters. Without knowing ahead of time what was written, it would be improbable for a reader to be able to decipher the sentence in the last two conditions. If the samples are illegible, they probably cannot be part of a GMP, concluding that writing may not be a GMP for most people. Although many of the samples received acceptable scores, writing for the fourth and fifth conditions were clearly and conclusively inferior to Raibert's sample. Most of the samples of the last two conditions were more than double or triple the size, and had altered spacing and forms from the first three conditions.

Sülzenbrück, Hegele, Rinkenauer and Heuer (2011) hypothesized that people who spend more time using a computer, therefore practicing their handwriting less, have less precision in their handwriting. Evaluation of participants in the current study who completed $50 \%$ or more of their writing using a computer did not confirm this conclusion. When evaluating the differences between those who did the majority of writing by hand and those who did not, no significant difference in overall quality appeared.

During the scoring process, researchers were aware of the identity of the letters. This allowed for an increase in likelihood that the letters would be recognizable (ex. looking for an "M" at the beginning of "Motor learning is fun."). More conservative scores would have resulted if the samples had been graded by someone who did not know which letters to look for. In this instance, the researchers were trying to generate the best scores possible in order to show any real differences between the groups and Raibert's sample. Statistical analysis of handwriting samples strengthened the current study. Aside from, Sülzenbrück, Hegele, Rinkenauer and Heuer (2011), most researchers have not employed statistical analysis for handwriting.

Because the results of this study were so dissimilar those of Raibert $(1976,1977)$, these authors suggest that practice is required to attain competence in foot writing. Some have accomplished foot dexterity in the absence of arms, a prime example being Christy Brown, Irish author and painter with cerebral palsy who wrote and painted with his left foot (later made into a movie called "My Left Foot"), or mouth dexterity in the absence of arm or foot functionality (Nonaka, 2013). However, we disagree with the notion that effector independence is automatic, as Raibert appeared to believe, and as Schmidt and co-authors have continued to suggest in all editions of Motor Learning and Performance (1991, 2000, 2004, 2008, 2014).

As to the second hypothesis, the authors cannot confirm that mature individuals have a GMP for writing, as Lee suggested (T. Lee, personal communication, September 25,2008 ), because mature adults' attempts were as uncontrolled and illegible as younger adults' for mouthwriting and footwriting. It appears that handwriting may be or may have become an especial skill (Keetch, Schmidt, Lee, \& Young, 2005) for all adults, suggested by Tim Lee (T. Lee, personal communications, September 25, 2008), as opposed to a GMP, as suggested by authors of motor learning textbooks.

Suddath (2009) suggested that using keyboards may cause a general loss of handwriting skills. Sülzenbrück et al. (2011) further reinforced the idea that mature adults performed better at a fine motor task with a pen than younger individuals, although on most skills, mature adults do not perform as well as young ones. Researchers have found that learning to write with novel effectors can be accomplished in a relatively short period of time (Schmidt, 1991; Schmidt \& Lee, 2014). In another case, after 
25 years, a person who did calligraphy by mouth was able to achieve master level (Nonaka, 2013).

In any case, samples from a total of three participants in 1942 and 1976 being held up as a GMP deserve to be examined, as good science would demand. Based on results from 31 participants, these investigators suggest a GMP for writing with different effectors does not exist.

\section{REFERENCES}

Accardo, A., Genna, M., \& Borean, M. (2013). Development, maturation and learning influence on handwriting kinematics. Human Movement Science, 32(1), 136-146.

Bara, F., \& Morin, M. F. (2013). Does the handwriting style learned in first grade determine the style used in the fourth and fifth grades and influence handwriting speed and quality? A comparison between French and Quebec children. Psychology in the Schools, 50(6), 601-617.

Berninger, V. (2012). Strengthening the Mind's Eye: The Case for Continued Handwriting Instruction. Principal, 28-31.

Berninger, V., Mizokawa, D., \& Bragg, R. (1991). Theory-based diagnosis and remediation of writing disabilities. Journal of School Psychology, 29(1), 57-79.

Bernstein, N. (1967). The co-ordination and regulation of movements. Oxford Univ. Press.

Carter, M. C., \& Shapiro, D. C. (1984). Control of sequential movements: Evidence for generalized motor programs. Journal of Neurophysiology, 52(5), 787-796.

Castiello, U., \& Stelmach, G. E. (1993). Generalized representation of handwriting: Evidence of effector independence. Acta Psychologica, 82(1-3), 53-68.

Connelly, V., Gee, D., \& Walsh, E. (2007). A comparison of keyboarded and handwritten compositions and the relationship with transcription speed. British Journal of Educational Psychology, 77(2), 479-492.

Feder, K. P., \& Majnemer, A. (2007). Handwriting development, competency, and intervention. Developmental Medicine \& Child Neurology, 49(4), 312-317.

Graham, S. (1999). Handwriting and spelling instruction for students with learning disabilities: A review. Learning Disability Quarterly, 22(2), 78-98.

Graham, S., Berninger, V., Abbott, R., Abbott, S., \& Whitaker, D. (1997). The role of mechanics in composing of elementary school students: A new methodological approach. Journal of Educational Psychology, 89(1), 170-182.

Graham, S., Harris, K. R., Mason, L., Fink-Shorzempa, B., Moran, S., \& Saddler, B. (2008). How do primary grade teachers teach handwriting? A national survey. Reading and Writing, 21(1-2), 49-69.

Graham, S., Struck, M., Santoro, J., \& Berninger, V. W. (2006). Dimensions of good and poor handwriting legibility in first and second graders: Motor programs, visual-spatial arrangement, and letter formation parameter setting. Developmental Neuropsychology, 29(1), $43-60$.

Graham, S., Weintraub, N., \& Berninger, V. W. (May/June 1998). The relationship between handwriting style and speed and legibility. Journal of Educational Research, 91(5), 290-296.

IBM (2018). SPSS v. 24.

Jones, D., \& Christensen, C. A. (1999). Relationship between automaticity in handwriting and students' ability to generate written text. Journal of Educational Psychology, 91(1), 44-49.

Keetch, K., Schmidt, R. A., Lee, T., \& Young, D. (2005). Especial skills: Their emergence with massive amounts of practice. Journal of Experimental Psychology. Human Perception \& Performance, 31(5), 970-978.

King, D. H. (2015). Congnitive benefits of handwriting. Dyslexia Tutor: News Release. Retrieved from https://dyslexia.wordpress.com/2015/04/02/cognitive-benefits-of-handwriting/. 
Lashley, K. S. (1942). The problem of cerebral organization in vision. In: J. Cattell (Ed.), Biological symposia, Vol. VII. Visual mechanisms (pp. 301-322). Lancaster, PA: Jaques Cattell Press.

Li, X., He, W., Li, C., Wang, Y., Slavens, B. A., \& Zhou, P. (2015). Motor unit number index examination in dominant and non-dominant hand muscles. Laterality: Asymmetries of Brain, Behaviour, and Cognition, 20(6), 699-710.

Marshall, J., \& Powers, J. (1969). Writing neatness, composition errors, and essay grades. Journal of Educational Measurement, 6(2), 97-101.

McCutchen, D. (1995). Cognitive processes in children's writing: Developmental and individual differences. Issues in Education: Contributions from Educational Psychology, 1, 123-160.

Merton, P. A. (1972). How we control the contraction of our muscles. Scientific American, $226(5), 30-37$.

Nonaka, T. (2013). Motor variability but functional specificity: The case of a C4 tetraplegic mouth calligrapher. Ecological Psychology, 25(2), 131-154.

Osiurak, F., Lesourd, M., Delporte, L., \& Rossetti, Y. (2018). Tool use and generalized motor programs: We all are natural born poly-dexters. Scientific Reports, 8(1), Article 10429.

Overvelde, A., \& Hulstijn, W. (2011). Handwriting development in grade 2 and grade 3 primary school children with normal, at risk, or dysgraphic characteristics. Research in Developmental Disabilities, 32(2), 540-548.

Pearson, N. (Producer) \& Sheridan, J. (Director). (1989). My Left Foot [Motion Picture]. United Kingdom: Ferndale Studio.

Phillips, J., \& Ogeil, R. (2010). Curved motions in horizontal and vertical orientations. Human Movement Science, 29(5), 737-750.

Raibert, M. (1976). A state space model for sensory motor control and learning. MIT Artificial Intelligence Memo No. 351, January.

Raibert, M. (1977). Motor control and learning by the state space model. Doctoral dissertation. Cambridge, MA: Massachusetts Institute of Technology.

Scardamalia, M., Bereiter, C., \& Goleman, H. (1982). The role of production factors in writing ability. In: M. Nystrand (Ed.), What writers know: The language, process, and structure of written discourse (pp. 173-210). New York: Academic Press.

Schmidt, R. A. (1991). Motor learning \& performance: From principles to practice. Champaign, IL: Human Kinetics.

Schmidt, R. A., \& Lee, T. D. (1988). Motor control and learning: A behavioral emphasis. Champaign, IL: Human Kinetics.

Schmidt, R. A., \& Lee, T. D. (2014). Motor control and learning (5th ed.). Champaign, IL: Human Kinetics.

Schmidt, R. A., \& Wrisberg, C. (2000). Motor learning and performance: From principle to application (2nd ed.). Champaign, IL: Human Kinetics.

Schmidt, R. A., \& Wrisberg, C. (2004). Motor learning and performance: From principle to application (3rd ed.). Champaign, IL: Human Kinetics.

Schmidt, R. A., \& Wrisberg, C. (2008). Motor learning and performance: From principle to application (4th ed.). Champaign, IL: Human Kinetics.

Schmidt, R. A., \& Lee, T. D. (2014). Motor learning and performance: From principle to application (5th ed.). Champaign, IL: Human Kinetics.

Shusterman, R. (2011) Muscle memory and the somaesthetic pathologies of everyday life. Human Movement, 12(1), 4-15.

Suddath, C. (2009). Mourning the death of handwriting. Time, August 3.

Sülzenbrück, S., Hegele, M., Rinkenauer, G., \& Heuer, H. (2011). The death of handwriting: Secondary effects of frequent computer use on basic motor skills. Journal of Motor Behavior, 43(3), 247-251.

Whitacre, C. A., \& Shea, C. H. The role of parameter variability on retention, parameter transfer, and effector transfer. Research Quarterly for Exercise and Sport, 73(1), 47-57. 
Wright, C. E. (1990). Generalized motor programs: Reexamining claims of effector independence in writing. In: M. Jeanerod (Ed.), Attention and Performance XIII, Motor Representation and Control (pp. 294-320). Hillsdale, NJ: Erlbaum.

Zubrzyecki, J. (2012). Strengthening the Mind's Eye: The case for continued handwriting instruction: The 21st century. Principal, 31, 28-31. 